\title{
REFLEXÕES SOBRE A REGIÃO METROPOLITANA DE MACEIÓ
}

\author{
Cid Olival Feitosa \\ Doutor em Desenvolvimento Econômico pela Universidade Estadual de Campinas \\ pela UNICAMP \\ Professor de economia da UFAL \\ Maceió- AL, Brasil. \\ Bruna Rocha Tenório de Gauw \\ Graduanda em Economia - FEAC/UFAL \\ Maceió- AL, Brasil
}

\begin{abstract}
Resumo - $O$ presente artigo tem como objetivo analisar as principais diferenças socioeconômicas entre os municípios que compõem a Região Metropolitana de Maceió (RMM) Inicialmente, faz um resgate histórico sobre a urbanização de Alagoas até a criação da RMM, pela assembleia legislativa estadual. Utiliza-se de dados secundários para apresentar alguns indicadores, dentre eles, taxa de analfabetismo, renda, faixa etária, índice de desenvolvimento humano municipal, dentre outros, evidenciando que Maceió, além de concentrar a maior parte da população da RMM, apresenta os melhores resultados dos índices analisados.
\end{abstract}

Palavras-chave: Região Metropolitana de Maceió; Desenvolvimento regional e urbano; Alagoas.

\section{REFLECTIONS ON THE METROPOLITAN REGION OF MACEIÓ}

\begin{abstract}
This article aims to analyze the main socioeconomic differences between the municipalities that make up the Maceió Metropolitan Region (RMM). Initially, it makes a historic rescue about the urbanization of Alagoas until the creation of RMM, by the state legislative assembly. Secondary data are used to present some indicators, such as illiteracy rate, income, age, municipal human development index, among others, showing that Maceió, besides concentrating most of the population of RMM, presents the best results of the indexes analyzed.
\end{abstract}

Keywords: Maceió Metropolitan Region; Regional and urban development; Alagoas.

\section{INTRODUÇÃO}

O processo de urbanização de Alagoas, embora se insira na dinâmica geral da urbanização brasileira e nordestina, ganhando impulso após os anos 1970, guarda algumas peculiaridades provenientes da sua estrutura econômica. Marcado pela herança do complexo econômico nordestino, com rígida estrutura produtiva, até a década de 1970 não se verificou um crescimento expressivo das funções urbanas. Na verdade, seu processo de urbanização foi muito lento e atomizado, concentrando-se basicamente na capital.

Esta fraca urbanização evidencia a conformação de um estado com regiões de economia predominantemente agrícolas e a existência de um grande número de pequenas cidades cuja base econômica é a atividade canavieira. Vale lembrar que após a década de 1960, em virtude das políticas de desenvolvimento regional implementadas pela Superintendência de Desenvolvimento do Nordeste (Sudene), como incentivos fiscais e financeiros ao setor industrial, e, posteriormente, com os investimentos estatais associados ao II Plano Nacional de 
Desenvolvimento (II PND) houve alguns ensaios (malogrados) de mudança na estrutura produtiva de Alagoas.

O não crescimento das atividades industriais ensejou uma grande expansão do setor de serviços, que representa mais de $70 \%$ do PIB estadual, e uma intensa concentração dessas atividades na capital e em alguns poucos municípios do entorno, resultando numa "urbanização concentrada".

Diante desses elementos, e com o objetivo de analisar as principais diferenças entre os municípios que compõem a Região Metropolitana de Maceió (RMM), o presente artigo está dividido em quatro seções, além desta introdução. Na segunda seção, faz-se um breve resgate histórico do processo de urbanização de Alagoas, buscando ressaltar a vinculação entre o surgimento das cidades e a principal atividade econômica do estado, a cana. Em seguida, apresenta-se a constituição da Região Metropolitana de Maceió, para, na seção seguinte, destacar as principais diferenças entre o núcleo central e os municípios que compõem esta área. Por fim, procede-se às considerações finais.

\section{NOTAS SOBRE A URBANIZAÇÃO DE ALAGOAS}

Os primeiros povoamentos de Alagoas datam da segunda metade do século XVI, quando uma expedição militar comandada por Duarte Coelho Pereira, donatário da capitania de Pernambuco, percorreu a costa em direção ao sul até o rio São Francisco, expulsando franceses que pirateavam pau-brasil e apaziguando os gentios (MUNIZ, 2011). Em virtude desta expedição, nasceram as povoações de Porto Calvo, ao norte, e Alagoas do Sul, atual Marechal Deodoro, no litoral central, assentadas na cultura da cana e na construção de engenhos. Penedo também data deste período, mas, segundo Diégues Júnior (2012), este foi o único povoamento alagoano cuja fundação se iniciou como arraial fortificado, por ser o ponto mais distante da sede da capitania e o limite territorial dela. Além disso, a ocupação do território penedense teve como impulso inicial o desenvolvimento da atividade pastoril, ainda que posteriormente tenha se integrado à dinâmica açucareira.

Um elemento importante para a ocupação do território alagoano foi a existência de inúmeros rios e lagoas, que além de servirem os vales férteis para os canaviais, funcionavam como meios de navegação e transporte do açúcar produzido, dando origem a diversos ancoradouros que exportavam seus produtos para o porto de Recife e, de lá, reexportavam o açúcar para a Europa. Segundo Diégues Júnior (2012), a atividade canavieira moldou a formação econômica, social e política de Alagoas, de modo que a criação de cidades ocorreu quase que exclusivamente em virtude da cultura açucareira. $\mathrm{O}$ surgimento de novos engenhos significava não apenas a expansão territorial dentro do âmbito rural, mas também a criação de 
novos núcleos de povoamento. A criação de gado era atividade subsidiária da cana, oscilando entre períodos de expansão e declínio, mas servindo como importante elemento de penetração do interior alagoano e constituição de importantes núcleos de povoamento.

No século seguinte, sob o domínio holandês, muitas povoações alagoanas foram alvo de constantes ataques. Algumas vilas foram facilmente conquistadas, engenhos devastados, populações despojadas dos seus haveres e obrigadas a migrar para as matas. Conforme relata Costa (1983, p. 22) "As habitações foram em grande parte destruídas pelo fogo. O tributo de guerra exigido foi colossal". Com o fim do domínio holandês, os núcleos populacionais mais expressivos, formados principalmente por escravos, ainda eram aqueles do início da colonização.

Aos poucos a economia açucareira foi se reerguendo e ganhando vulto para o conjunto da capitania. Houve um surto de prosperidade e riqueza, levando à criação da comarca das Alagoas, em 1706, com sede em Alagoas do Sul. Para Costa (1983), o desenvolvimento era visível; em 1730, havia 47 engenhos de açúcar, 10 freguesias e uma renda bastante elevada, além de um aparelhamento jurídico e administrativo mais completo no território. Este seria o primeiro passo para a autonomia administrativa que se verificou no século seguinte.

No final do século XVIII registra-se a formação do arraial de Maceió. Alguns historiadores, dentre eles, Craveiro Costa, defendem que a povoação surgiu em virtude de um engenho de mesmo nome e se desenvolveu em função das atividades comerciais vinculadas ao porto de Jaraguá, cujas marés calmas e boa profundidade permitiam excelente ancoradouro. Para Faria (2004), outros elementos importantes para o desenvolvimento de Maceió foram a sua localização, que era bastante favorável do ponto de vista defensivo, e a facilidade de escoamento da produção, uma vez que permitia rápido acesso às áreas interioranas da capitania pelo vale do rio Mundaú onde outros povoados se formaram e onde se instalaram sedes de engenhos de açúcar. Assim, em 1815, Maceió foi elevada à categoria de vila, experimentando grande crescimento econômico ao longo de todo o século XIX, principalmente após 1839, quando se tornou capital da Província.

O século XVIII assinala também a expansão do algodão no território alagoano, que se deu de forma diferente da cana-de-açúcar e da pecuária. Enquanto a primeira se estendia pelos tabuleiros litorâneos e a segunda ocupava a periferia da atividade açucareira, o algodão se expandiu pelo agreste e adentrou o sertão, criando uma nova extensão de povoamento. Além disso, favoreceu a dinamização da economia sertaneja à medida que se formava um complexo econômico de beneficiamento através da pecuária e do algodão (ALTAVILA, 1962). 
As exportações de açúcar e de algodão pelo porto de Jaraguá contribuíram para a formação de uma burguesia mercantil, estimulando o adensamento populacional e a expansão das funções urbanas de Maceió. Como destacou Corrêa (1994), com a criação deste porto e o estabelecimento da Alfândega, os engenhos alagoanos passaram a exportar diretamente para Europa. Maceió passou a comandar boa parte da comercialização da produção canavieira do estado, diminuindo significativamente a influência de outros portos menores e exercendo domínio sobre as cidades de Santa Luzia do Norte, Marechal Deodoro, Atalaia, São Miguel dos Campos e Palmeiras dos Índios.

Apesar da importância do porto de Jaraguá, em 1872, Maceió aparecia como a quarta cidade mais populosa de Alagoas, com 27.703 habitantes, ficando atrás de Penedo (35.198 habitantes), Viçosa (33.433 habitantes) e União dos Palmares (29.754 habitantes) (IBGE, 1872). A primazia de Penedo ocorria pela sua posição estratégica às margens do rio São Francisco, funcionando como centro importador e exportador de mercadorias para várias cidades de Alagoas, Sergipe e Bahia, e importante entreposto de comércio interprovincial de escravos (TEIXEIRA, 2016). Ademais, o desenvolvimento da cultura algodoeira e a crescente demanda verificada na década anterior, em virtude da guerra de Secessão dos EUA, transformaram Penedo numa das mais influentes e importantes cidades do sul de Alagoas.

O desenvolvimento do transporte ferroviário, no final do século XIX, promoveu uma reconfiguração do espaço urbano alagoano, fazendo surgir novos centros de influência no estado e alterando a importância de antigas cidades. Neste período, Viçosa surge como centro de grande atração para a produção de algodão e criação de gado. Palmeiras dos Índios passa a exercer grande influência sobre as áreas do agreste e sertão alagoano e até mesmo sobre o agreste pernambucano. Observa-se o surgimento de pequenos estabelecimentos agrícolas e a expansão do cultivo de fumo em Arapiraca, ocasionando o desenvolvimento no setor de serviços e do comércio. Penedo vai perdendo a centralidade que exercia numa vasta área que ia de Alagoas a Sergipe e Maceió vai assumindo, cada vez mais, a função de principal centro urbano de Alagoas, com diversas fábricas instaladas, principalmente têxteis (CORRÊA, 1994).

Em 1910, Maceió já era a cidade mais populosa do estado, com 61.281 habitantes. Este período assinala a modernização de algumas atividades em Alagoas, como a estruturação das usinas e o surgimento de fábricas de tecido, intensificando as atividades urbana do estado. Segundo Carvalho (1980), no início do século XX, verificava-se a existência de seis fábricas têxteis de grande porte em Alagoas. Além de Carmem, inaugurada em 1888, a Progresso e a Cachoeira, ambas em Rio Largo. Em 1892, foi instalada no Pilar a Companhia Pilarense de Fiação e Tecidos e, finalizando a década, a Companhia Industrial Penedense, instalada ao 
final de 1898 na cidade de Penedo. Além disso, registra-se a construção da hidrelétrica de Paulo Afonso e algumas estradas de rodagem interligando o agreste e o sertão alagoano.

Além da ascensão da indústria, o setor algodoeiro também vinha se beneficiando do próprio desenvolvimento do estado no início do século. Nesse período, surgiram várias cooperativas de crédito rural e se instalou em Maceió uma agencia do Banco do Brasil, em 1914; no ano seguinte, criava-se o Banco do Estado. Nos anos 1920, chegava à capital o Banco de Londres (CARVALHO, 1980). Até a década de 1930, as atividades urbanas de Alagoas se expandiram pelo aumento das relações econômicas de Maceió com as cidades do interior. Porém, este período também marca a decadência do porto de Jaraguá, que se tornou obsoleto para receber navios cada vez maiores, desencadeando o fim da expansão das ferrovias alagoanas.

Com o avanço da industrialização e a integração do mercado nacional foi se consolidando uma articulação comercial entre as diversas regiões brasileiras, que teve como um dos seus elementos fundamentais o desenvolvimento do transporte rodoviário. Em Alagoas, o transporte rodoviário desenvolveu-se na década de 1940, ampliando as relações com Recife e Salvador, que se destacavam como as principais cidades do Nordeste. É importante destacar que o desenvolvimento do transporte rodoviário em Alagoas não surge para beneficiar o escoamento da produção do setor sucroalcooleiro, mas para interligar Maceió a outros centos urbanos maiores.

Os anos 1950 marcam a expansão da urbanização brasileira. Há intensificação do aumento populacional nas cidades, em virtude das atividades industriais, notadamente no Sudeste. Crescem os movimentos migratórios rural-urbano e a população urbana vai ultrapassar a população rural. O rápido crescimento urbano agravou os problemas de infraestrutura das cidades, como a falta de habitação, trabalho e transportes.

Acompanhado a dinâmica do restante do país, a partir da década de 1960, observou-se o aumento da população em Maceió, impulsionado pelo fluxo migratório campo-cidade, em decorrência da grande concentração fundiária, das novas perspectivas que se abriam na capital e do início da modernização agrícola. Em virtude destes acontecimentos, Maceió apresentou rápido crescimento populacional, passando de 168.055 habitantes, em 1960, para 263.670 habitantes, em 1970, um crescimento maior do que aquele verificado para o Brasil.

Para dar suporte à maior demanda habitacional surgiu o Instituto de Pensão e Aposentadoria do Estado de Alagoas (IPASEAL) e a Companhia de Habitação Popular de Alagoas $(\mathrm{COHAB})$, principais órgãos responsáveis pela política de urbanização e habitação no estado, a partir dos anos 1960. Com o apoio do Sistema Financeiro de Habitação, diversos 
conjuntos habitacionais populares foram criados, porém foram construídos em áreas distantes do centro e dos postos de trabalho, devido ao baixo valor do solo nas regiões periféricas da cidade, carentes de infraestrutura e de investimentos públicos.

De modo geral, a população migrante, não conseguindo se enquadrar no espaço urbano da capital, dado o alto preço dos imóveis, aluguéis e terrenos, foi "expulsa" para a periferia da cidade, fixando residência nos municípios limítrofes e/ou nos conjuntos habitacionais próximos, em áreas que, por sua distância e carência dos equipamentos e serviços urbanos, tiveram valorização relativamente menor e, portanto, onde o custo monetário da habitação era mais baixo.

Corroborando tal assertiva, embora as taxas de crescimento anual da população urbana de Maceió tenham sido expressivas nos anos 1980 e 1990, com 4,5\% e 3,7\%, respectivamente, os municípios do entorno, como Marechal Deodoro, Barra de São Miguel, Messias e Rio Largo apresentaram taxas superiores às da capital alagoana, conforme dados da Tabela 1.

Este aumento demográfico fez com que se expandisse a área urbana da capital, ultrapassando seus limites municipais, mas preservando áreas subutilizadas e rarefeitas no interior do próprio tecido urbano, servindo, posteriormente, a um processo especulativo. Como resultado do crescimento expressivo das áreas contíguas a Maceió, onde o mercado especulativo ainda não havia alterado incisivamente o valor do solo, foi-se formando, inicialmente, uma aglomeração urbana e, posteriormente, um processo de "metropolização" em Alagoas.

Tabela 1: Alagoas: - Taxa de crescimento anual da população urbana - 1980/2010 $(\%)$

\begin{tabular}{|c|c|c|c|c|}
\hline Municípios & 1980 & 1991 & 2000 & 2010 \\
\hline Barra de Santo Antônio & 5,0 & 4,0 & 6,0 & 3,3 \\
\hline Barra de São Miguel & 5,8 & 8,9 & 4,6 & 2,2 \\
\hline Coqueiro Seco & 4,4 & 1,8 & 0,9 & 0,8 \\
\hline Maceió & 4,5 & 3,7 & 3,5 & 1,6 \\
\hline Marechal Deodoro & 5,5 & 4,2 & 8,2 & 3,8 \\
\hline Messias & 9,1 & 8,6 & 4,7 & 4,1 \\
\hline Paripueira & - & - & - & 3,6 \\
\hline Pilar & 4,7 & 3,8 & 2,7 & 1,2 \\
\hline Rio Largo & 0,7 & 4,7 & 2,9 & 1,1 \\
\hline Santa Luzia do Norte & 4,0 & 6,5 & 0,8 & 1,3 \\
\hline Satuba & 4,0 & 5,1 & 6,2 & 2,5 \\
\hline Alagoas & $\overline{4,5}$ & 3 & 2,9 & 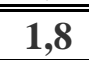 \\
\hline
\end{tabular}

Fonte: IBGE - Censo Demográfico

\section{A FORMAÇÃO DA REGIÃO METROPOLITANA DE MACEIÓ}

\footnotetext{
${ }^{1}$ Cabe advertir que a criação de regiões metropolitanas provém de decisões dos executivos estaduais, aprovadas em Assembleias Legislativas, muitas vezes não aparecendo na literatura especializada, que leva em consideração diversos fatores para estabelecer tal classificação. No Nordeste, por exemplo, o IBGE considera apenas as regiões metropolitanas de Salvador, Recife e Fortaleza.
} 
No Brasil, a criação de regiões metropolitanas data da década de 1970, quando alguns estados experimentaram um intenso crescimento populacional no entorno das suas capitais. Parte deste processo foi decorrente do avanço da industrialização e da constatação de que o lócus da produção econômica havia se deslocado para os grandes centros urbanos, na medida em que as cidades passavam a ser vistas não apenas como lugar de vivência, mas também como importantes unidades de produção.

Com a Constituição de 1988, uma nova fase seria verificada, pois a Carta Magna concedeu aos estados, mediante lei complementar, a possibilidade de instituição de regiões metropolitanas, a partir de decisões políticas, sem a definição de parâmetros ou características estabelecidas nacionalmente. $\mathrm{O}$ resultado foi a criação de um expressivo número de regiões metropolitanas sem que houvesse, necessariamente, uma metrópole.

Em Alagoas, conforme Santos Filho (2018), entre 1998 e 2013, foram criadas, através de projetos de lei do legislativo e sancionados pelo executivo estadual, nove regiões metropolitanas, a saber: Região Metropolitana de Maceió (1998), Região Metropolitana do Agreste (2009), Região Metropolitana do Vale do Paraíba (2011), Região Metropolitana da Zona da Mata (2011), Região Metropolitana de Palmeira dos Índios (2012), Região Metropolitana do São Francisco (2012), Região Metropolitana dos Caetés (2012), Região Metropolitana do Sertão (2012), Região Metropolitana do Médio São Francisco (2013)².

A Região Metropolitana de Maceió (RMM), objeto deste artigo, foi criada em 1998, pela Lei Complementar Estadual n ${ }^{\circ}$ 18. Inicialmente, a área era composta pelos municípios de Barra de Santo Antônio, Barra de São Miguel, Coqueiro Seco, Maceió, Marechal Deodoro, Messias, Paripueira, Pilar, Rio Largo, Santa Luzia do Norte e Satuba. Em 2013, a área da RMM foi ampliada pela primeira vez, através da Lei Estadual $n^{\circ} 38$, que adicionou o município de Atalaia. Em 2014, uma nova mudança ocorreu com a implementação da Lei Complementar $n^{\circ} 40$, que incorporou o município de Murici, estabelecendo a composição atual da RMM, conforme Figura 1.

Figura 1 - Mapa da Região Metropolitana de Maceió - RMM

\footnotetext{
${ }^{2}$ Para uma análise dos municípios que compõem cada região metropolitana, ver Santos Filho (2018). 


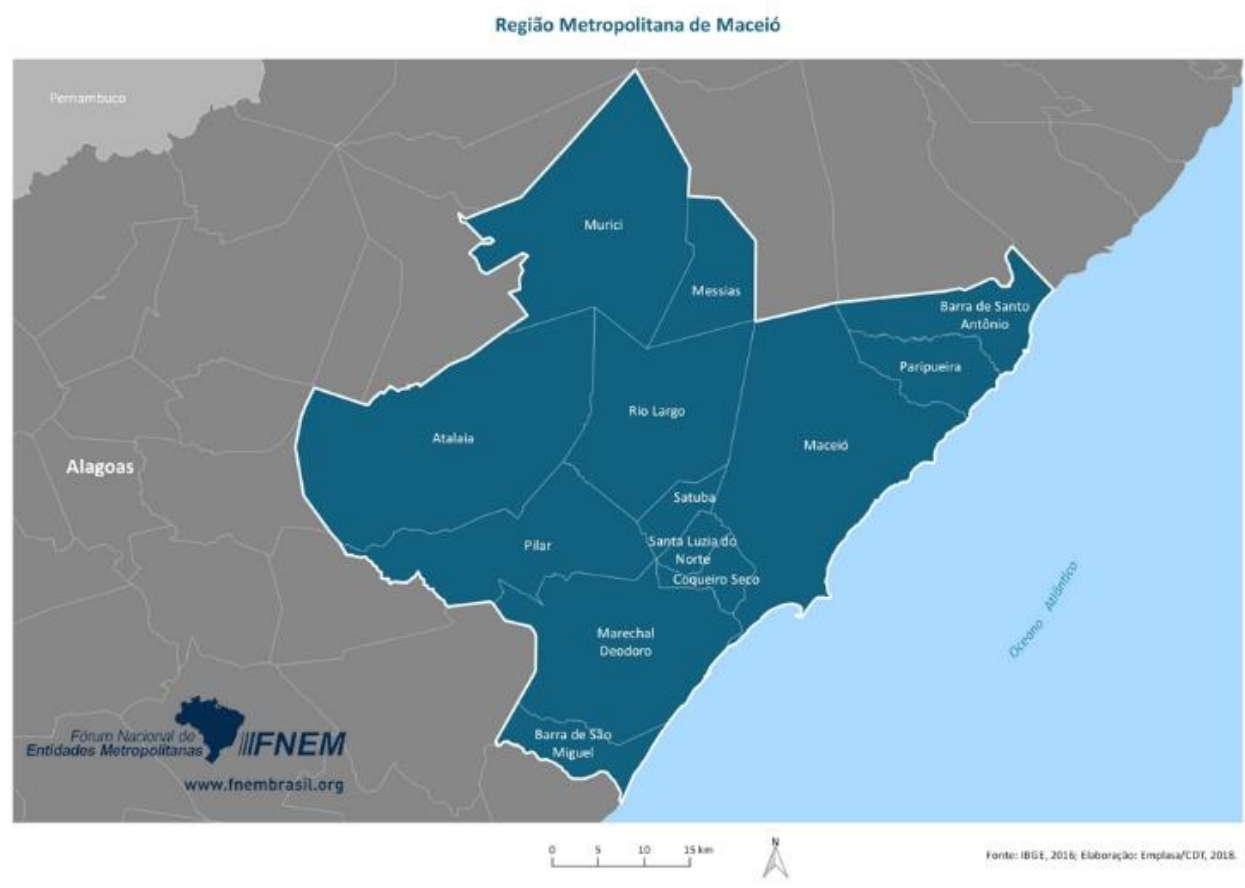

Segundo a proposta de criação, a formação da RMM visava integrar a organização, o planejamento e a execução das funções públicas de interesse comum, além de melhorar a infraestrutura existente e estimular a geração de emprego e renda dos municípios participantes (SILVA FILHO, 2018). No entanto, pouco se observou da implementação de políticas públicas que promovessem, de fato, tal integração. Na verdade, houve apenas a institucionalidade de tal formação urbana, sem a discussão ou implementação de ações concretas que pudessem modificar a realidade dos municípios participantes. Ainda assim, a RMM possui grande importância demográfica e econômica para o estado de Alagoas. Em 2010, abrigava 38,8\% da população estadual, com 1.210 mil habitantes, conforme dados da Tabela 2. Com a incorporação dos municípios de Atalaia e Murici, a RMM passou a abrigar 41,1\% da população estadual. Segundo o IBGE (2019), em 2018, a estimativa para a população da RMM, com a atual configuração, era de 1.330 mil habitantes.

Vale destacar que Maceió concentrava cerca de 80,6\% da população total da RMM, dada a maior oferta de emprego, bens e serviços. Esse adensamento populacional, no entanto, se traduziu em um processo de ocupação desordenado, com pessoas residindo em áreas desfavoráveis à habitação, como encostas, grotas, locais próximos a lixões, dentre outras. Além disso, à medida em que avançava a urbanização da capital alagoana, duas grandes mudanças foram observadas: de um lado, a verticalização das áreas ocupadas por pessoas de média e alta rendas; de outro, a expansão horizontal nas áreas mais periféricas da cidade, cuja rendas classificavam-se entre média baixa e baixa (IPEA, 2001). Outra característica verificada em Maceió, mas comum às áreas periféricas de diversas cidades, é a grande carência de 
investimentos públicos nos serviços de transporte, educação e saúde, além da elevada taxa de criminalidade e da predominância do trabalho informal.

Tabela 2: Região Metropolitana de Maceió - População total 2000/2010

\begin{tabular}{l|r|r}
\hline \hline \multicolumn{1}{c|}{ Unidades } & \multicolumn{1}{c|}{$\mathbf{2 0 0 0}$} & \multicolumn{1}{c}{$\mathbf{2 0 1 0}$} \\
\hline \hline Barra de Santo Antônio & 11.351 & 14.230 \\
Barra de São Miguel & 6.379 & 7.574 \\
Coqueiro Seco & 5.134 & 5.526 \\
Maceió & 797.759 & 932.748 \\
Marechal Deodoro & 35.866 & 45.977 \\
Messias & 11.990 & 15.682 \\
Paripueira & 8.049 & 11.347 \\
Pilar & 31.201 & 33.305 \\
Rio Largo & 62.510 & 68.481 \\
Santa Luzia do Norte & 6.388 & 6.891 \\
Satuba & 12.555 & 14.603 \\
\multicolumn{1}{c|}{ RMM } & $\mathbf{9 8 9 . 1 8 2}$ & $\mathbf{1 . 2 1 0 . 9 4 1}$ \\
\hline \hline \multicolumn{1}{c|}{ Alagoas } & $\mathbf{2 . 8 2 2 . 6 2 1}$ & $\mathbf{3 . 1 2 0 . 4 9 4}$ \\
\hline \hline
\end{tabular}

Fonte: IBGE - Censo Demográfico

Sob o ponto de vista econômico, a RMM respondia em 2016 por $51,7 \%$ de toda a riqueza gerada no estado (Tabela 3). De acordo com dados do IBGE, o PIB alagoano foi de R $\$ 49,456$ bilhões, registrando queda de $-1,4 \%$ em relação a 2015, porém, menor do que a verificada para o Brasil, que foi de $-3,3 \%$. Entre os setores que compõem o indicador, a agropecuária apresentou crescimento nos últimos anos, com participação de 15,1\%. A indústria, depois do crescimento da construção civil, que perdurou até 2011, vem diminuindo continuamente, perfazendo $12,4 \%$. Já os serviços respondiam por $72,5 \%$ de toda a produção alagoano. Não é demais lembrar que o grande peso do setor de serviços deve-se à elevada concentração fundiária e à baixa diversificação agrícola e industrial do estado, impactando sobre a estrutura urbana dos municípios.

Tabela 3: PIB a preços correntes, PIB per capita e Participação sobre o PIB - RMM - 2016

\begin{tabular}{l|c|c|c}
\hline \hline \multicolumn{1}{c|}{ Município } & PIB (mil reais) & $\begin{array}{c}\text { PIB per } \\
\text { capita (R\$) }\end{array}$ & $\begin{array}{c}\text { Participação } \\
\text { no PIB } \\
\text { estadual }\end{array}$ \\
\hline \hline Atalaia $^{*}$ & 670.061 & 14.098 & 1,4 \\
Barra de Santo Antônio & 171.195 & 10.761 & 0,3 \\
Barra de São Miguel & 157.937 & $18.946,40$ & 0,3 \\
Coqueiro Seco & 60.700 & 10.297 & 0,1 \\
Maceió & 21.306 .116 & 20.853 & 43,1 \\
Marechal Deodoro & 1.637 .084 & 31.656 & 3,3
\end{tabular}




\begin{tabular}{l|c|c|c} 
Messias & 174.076 & 9.786 & 0,4 \\
Murici* $^{*}$ & 255.695 & 8.984 & 0,5 \\
Paripueira & 154.306 & 11.801 & 0,3 \\
Pilar & 421.360 & 11.893 & 0,9 \\
Rio Largo & 981.595 & 12.969 & 2,0 \\
Santa Luzia do Norte & 111.927 & 15.214 & 0,2 \\
Satuba & 139.026 & 10.057 & 0,3 \\
\multicolumn{1}{c|}{ RMM } & $\mathbf{2 6 . 2 4 1 . 0 7 8}$ & - & $\mathbf{5 3 , 1}$ \\
\hline \hline
\end{tabular}

Fonte: IBGE - Contas Regionais

*Municípios incluídos a partir de 2013 e 2014.

Além da participação geral no PIB, a RMM também apresenta grande importância setorial, concentrando $14,3 \%$ do valor adicionado da agricultura, $69,4 \%$ da indústria e 55,3\% dos serviços. Tais resultados são fruto da elevada produção agrícola canavieira, principal cultura agrícola do estado, uma vez que os municípios desta área são responsáveis por 24,7\% de toda a cana produzida em 2016. Ademais, a concentração industrial é explicada pelo fato da RMM abrigar os dois principais Polos Industriais do estado, o Polo Multisetorial Gov. Luiz Cavalcante, localizado em Maceió, e Polo Multifabril Industrial José Aprígio Vilela, localizado em Marechal Deodoro; e da elevada participação do setor de serviços, por sediar a administração pública estadual e municipal e pelo maior dinamismo que uma capital de estado exerce sobre os demais municípios.

Em 2016, Maceió possuía a maior participação sobre a composição do PIB estadual, com 43,1\%. A principal atividade econômica da capital alagoana era o setor de serviços, com 55,3\% de toda a produção do município. Assim como Maceió, os municípios de Barra de São Miguel, Murici, Paripueira, Rio Largo, Santa Luzia do Norte e Satuba apresentam dependência do setor de serviços como a maior atividade produtiva.

O município de Marechal Deodoro se destaca por apresentar como maior atividade produtiva o setor industrial, que corresponde a 30,4\% do que é produzido no município, além de apresentar o segundo maior PIB entre os municípios que compõe a região metropolitana, com $\mathrm{R}$ \$ 3,3 bilhões, isso se deve a instalação do Polo Multifabril, que conta principalmente com indústrias da Cadeia Produtiva da Química e da produção de Plástico. Pilar também apresenta a indústria como principal atividade econômica, na cidade está instalada a unidade de processamento de gás natural de Alagoas, que representa 30,8\% do PIB municipal. Os demais municípios que formam a RMM, possuem como principal atividade produtiva o setor primário, 
e dentre eles Rio Largo e Atalaia apresentam cerca de $2 \%$ e $1 \%$, respectivamente, sobre a participação no PIB estadual.

Em todos os municípios, os serviços públicos de administração, educação e saúde apresentaram elevada participação na composição do PIB, cerca de $24,3 \%$, o que evidencia a baixa participação do setor privado no estado e o número significativo de municípios que dependem dos recursos governamentais para se manter.

\section{DIFERENÇAS INTRAMETROPOLITANAS}

A formação da Região Metropolitana de Maceió, embora concentre elevado contingente populacional e importante dinamismo econômico, guarda profundas diferenças socioespaciais entre os seus municípios.

De modo geral, em 2010, a RMM era formada por uma população adulta (20 a 59 anos de idade), ainda que entre as faixas etárias individuais se destacassem as faixas de 10 a 14 anos, para homens, e de 25 a 29 anos, para mulheres, conforme Gráfico 1. Entre os municípios, Atalaia era aquele que possuía o maior percentual de jovens (0 a 19 anos), com 43,7\%, e Coqueiro Seco, o maior número de idosos (60 anos e mais), com 9,4\%. Maceió destacava-se como o município que possuía a maior população adulta (57,5\% do total), explicada, em parte, pelas maiores oportunidades de emprego e maior oferta de serviços, que, além do crescimento vegetativo, atrai contingentes populacionais de outros municípios e regiões.

Gráfico 1: Pirâmide Etária - RMM - 2010

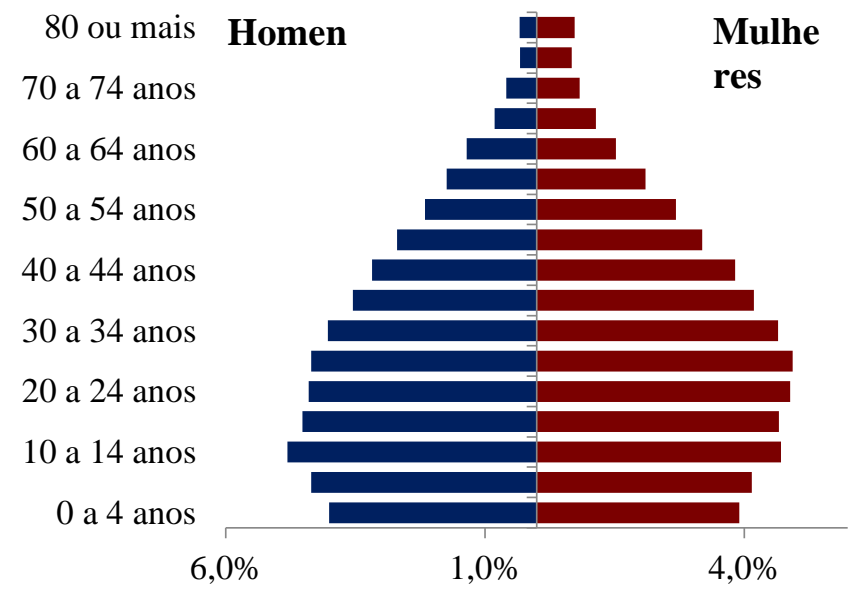

Fonte: IBGE (2010)

Cabe lembrar que Alagoas é um dos estados que possuem os piores indicadores econômicos e sociais. No ranking brasileiro, apresenta o pior índice de analfabetismo e a maior proporção de pobres, resultados da falta de diversificação produtiva e da extrema concentração fundiária que o estado apresenta. 
O Índice de Desenvolvimento Humano Municipal (IDHM) da Região Metropolitana de Maceió, em 2000, equivalia a 0,567, faixa considerada como Baixo Desenvolvimento Econômico; já em 2010, o IDHM aumentou para 0,702, considerado como Alto Desenvolvimento Humano. A melhora deste indicador decorre da implementação de políticas públicas, por parte do governo federal, ao longo dos anos 2000, que possibilitou maior acesso da população a bens e serviços. Especificamente sobre a variação do IDHM, o principal fator de influência foi o índice de educação dos municípios, que subiu de 0,402, em 2000, para 0,608, em 2010. Entre os municípios que compõe a região metropolitana, Maceió foi o que apresentou maior IDHM, equivalente a 0,721 , número próximo ao desempenho brasileiro, que em 2010 resultou em 0,721, conforme pode ser observado na Tabela 4.

Apesar de apresentar alto grau de desenvolvimento humano, a RMM está na última posição do ranking divulgado pelo PNUD, que mostra os indicadores de vinte Regiões Metropolitanas, com dados referentes a 2010.

Tabela 4: Evolução do Índice de Desenvolvimento Econômico Municipal - 2000- 2010

\begin{tabular}{l|c|c}
\hline \multirow{2}{*}{\multicolumn{1}{c|}{ Lugar }} & \multicolumn{2}{c}{ IDHM } \\
\cline { 2 - 3 } & $\mathbf{2 0 0 0}$ & $\mathbf{2 0 1 0}$ \\
\hline Brasil & 0,612 & 0,727 \\
Alagoas & $\mathbf{0 , 4 7 1}$ & $\mathbf{0 , 6 3 1}$ \\
Barra de Santo Antônio & 0,378 & 0,557 \\
Barra de São Miguel & 0,44 & 0,615 \\
Coqueiro Seco & 0,466 & 0,586 \\
Maceió & 0,584 & 0,721 \\
Marechal Deodoro & 0,463 & 0,642 \\
Messias & 0,379 & 0,568 \\
Paripueira & 0,423 & 0,605 \\
Pilar & 0,418 & 0,610 \\
Rio Largo & 0,505 & 0,643 \\
Santa Luzia do Norte & 0,434 & 0,597 \\
Satuba & 0,543 & 0,660 \\
\hline
\end{tabular}

Fonte: PNUD (2018) 
Para analisar o perfil educacional da Região Metropolitana, foi selecionado o indicador relativo a taxa de analfabetismo da população com 15 anos ou mais de idade. A RMM apresentou taxa de analfabetismo de $13,6 \%$, em 2010, número muito acima do que os estados vizinhos de Salvador e Recife apresentaram, $4,9 \%$ e $8,7 \%$ respectivamente.

Na última década, ocorreu um movimento de melhoria dos níveis educacionais do estado, conforme dados da Tabela 5. As reduções mais significativas foram verificadas nos municípios de Barra de Santo Antônio (-14,8\%), Pilar (-12,5\%) e Barra de São Miguel (-12,5\%), porém esses números ainda apresentam valor bastante elevado, evidenciando os problemas estruturais de Alagoas. No entanto, de modo geral, as taxas de educação alagoanas demostram baixas alterações de 2000 a 2010. O estado não acompanhou o ritmo de redução da taxa de alfabetismo apresentado pelo restante do país. Em 2010, a taxa de analfabetismo em Alagoas ainda correspondia a $24,3 \%$, configurando o menor desempenho entre os estados nordestinos.

Tabela 5: Taxa de analfabetismo - pessoas com 15 anos ou mais - RMM

\begin{tabular}{l|c|c}
\hline \multirow{2}{*}{\multicolumn{1}{c|}{ Municípios }} & \multicolumn{2}{c}{ Taxa de analfabetismo } \\
\cline { 2 - 3 } & $\mathbf{2 0 0 0}$ & $\mathbf{2 0 1 0}$ \\
\hline Barra de Santo Antônio & 42,7 & 27,9 \\
Barra de São Miguel & 36,2 & 23,7 \\
Coqueiro Seco & 35,7 & 28,2 \\
Maceió & 16,9 & 11,9 \\
Marechal Deodoro & 34,0 & 21,9 \\
Messias & 38,7 & 29,9 \\
Paripueira & 33,1 & 24,2 \\
Pilar & 37,1 & 24,5 \\
Rio Largo & 26,7 & 18,3 \\
Santa Luzia do Norte & 29,8 & 23,1 \\
Satuba & 24,4 & 18,5 \\
\hline Fonte: PNUD (2018)
\end{tabular}

Fonte: PNUD (2018) 
Além dos piores índices de educação, o estado também apresentava a segunda menor renda per capita em 2010, cerca de $\mathrm{R} \$ 432,56$, atrás apenas do estado do Maranhão, que possuía renda per capita de $\mathrm{R} \$ 360,34$. O valor demonstra que a renda per capita alagoana está $46 \%$ abaixo da renda nacional. Há uma melhoria no indicador apenas quando a RMM é analisada, já que esta apresenta renda per capita de $\mathrm{R} \$ 691,51$ mensais. A baixa renda per capita está relacionada a estagnação da economia alagoana a partir dos anos 1990 que se origina com a desorganização das finanças públicas do estado para atender o setor sucroalcooleiro.

A concentração de renda na RMM não obteve grande alterações de 2000 para 2010. O índice de Gini, que mede a desigualdade, manteve-se em 0,63, além de que o percentual da renda apropriado pelos $10 \%$ da população mais rica ainda em 2010 correspondia a mais de $52,3 \%$, resultado da alta concentração de terra e renda no estado. Em 2010, cerca de 33,8\% da população da RMM apresentava rendimento familiar de até um salário mínimo. (Tabela 6). Nas classes de renda acima de dez salários mínimos, verifica-se uma concentração ainda mais elevada em Maceió, que detém 95,8\% da população da área metropolitana nessa condição de renda.

Tabela 6: Pessoas de 10 anos ou mais de idade, por classes de rendimento nominal mensal (\%) - RMM - 2000/2010

\begin{tabular}{l|c|c}
\hline \multirow{2}{*}{$\begin{array}{l}\text { Classes de rendimento nominal } \\
\text { mensal }\end{array}$} & 2000 & 2010 \\
\cline { 2 - 3 } & 19,2 & 33,8 \\
Até 1 salário mínimo & 13,6 & 15,7 \\
Mais de 1 a 2 salários mínimos & 5,2 & 4,7 \\
Mais de 2 a 3 salários mínimos & 5,3 & 4,3 \\
Mais de 3 a 5 salários mínimos & 5,0 & 4,2 \\
Mais de 5 a 10 salários mínimos & 2,4 & 1,5 \\
Mais de 10 a 20 salários mínimos & 1,5 & 0,7 \\
Mais de 20 salários mínimos & 47,6 & 35,0 \\
Sem rendimento &
\end{tabular}

Fonte: IBGE - Censo Demográfico (2000 e 2010). 
A estrutura econômica de Alagoas ainda fornece poucos empregos formais devido à sua pouca diversificação. O serviço público concentra boa parte dos empregos; a indústria de transformação, principalmente o setor de alimentos, em função do setor sucroalcooleiro, é o segundo setor com o maior percentual de trabalhadores. Porém, os setores de comércio e serviços ultrapassam a quantidade dos trabalhadores do setor público e da indústria. $\mathrm{O}$ indicador que mede a taxa de desocupação de pessoas com 18 anos ou mais, demonstrou que, em 2010, a RMM apresentava 12,4\% da população desocupada, atrás apenas das áreas metropolitanas de Recife e Salvador.

A melhoria de alguns indicadores levou a uma redução da pobreza. Entre 2000 e 2010, o índice, que considera pessoas que recebem até meio salário mínimo mensalmente, passou de $37,0 \%$ para $19,0 \%$. Ainda assim, a média verificada para a RMM, embora seja melhor do que a média estadual, está acima dos indicadores nacionais. Dentro da RMM, em 2010, os municípios de Barra de Santo Antônio e Messias possuíam mais de $40 \%$ da sua população em condição de pobreza. Em contraposição, Maceió apresentava a melhor posição, com 15,6\%, próximo da média nacional. No que diz respeito à população extremamente pobre, os destaques negativos foram para Barra de Santo Antônio e Pilar, com 18,9\% e 15,2\%, respectivamente. Mais uma vez, Maceió foi o município da região metropolitana melhor classificado (Tabela 7).

Tabela 7 - RMM: Percentual de pobres e extremamente pobres - 2000 e 2010

\begin{tabular}{l|c|c|c|c}
\hline \hline \multirow{2}{*}{\multicolumn{1}{c|}{ Espacialidade }} & \multicolumn{2}{c|}{$\begin{array}{c}\text { \% de extremamente } \\
\text { pobres }\end{array}$} & \multicolumn{2}{c}{ \% de pobres } \\
\cline { 2 - 5 } & $\mathbf{2 0 0 0}$ & $\mathbf{2 0 1 0}$ & $\mathbf{2 0 0 0}$ & $\mathbf{2 0 1 0}$ \\
\hline \hline Barra de Santo Antônio & 36,8 & 18,9 & 67,4 & 44,2 \\
Barra de São Miguel & 20,1 & 9,2 & 50,7 & 23,9 \\
Coqueiro Seco & 31,1 & 14,3 & 60,0 & 31,1 \\
Maceió & 11,5 & 5,3 & 31,9 & 15,6 \\
Maceió & 14,4 & 6,7 & 37,0 & 19,0 \\
Marechal Deodoro & 26,5 & 13,3 & 57,9 & 32,0 \\
Messias & 35,4 & 13,8 & 66,7 & 41,0 \\
Paripueira & 30,9 & 11,0 & 64,5 & 32,5 \\
Pilar & 29,9 & 15,2 & 60,3 & 35,3 \\
Rio Largo & 20,7 & 7,9 & 47,4 & 24,3 \\
Santa Luzia do Norte & 27,7 & 13,3 & 63,2 & 32,7 \\
São Miguel dos Campos & 19,2 & 10,1 & 53,8 & 28,1 \\
Satuba & 23,1 & 7,1 & 46,3 & 26,5 \\
\hline \hline & $\mathbf{1 4 , 4}$ & $\mathbf{6 , 7}$ & $\mathbf{3 7 , 0}$ & $\mathbf{1 9 , 0}$ \\
\hline \hline Alagoas & 32,0 & 16,7 & 56,8 & 34,3 \\
\end{tabular}




\begin{tabular}{l|l|l|l|l} 
Brasil & 12,5 & 6,6 & 27,9 & 15,2 \\
\hline \hline
\end{tabular}

Fonte: PNUD (2018)

\section{CONSIDERAÇÕES FINAIS}

A formação de vilas e cidades em Alagoas se deu de forma muito lenta, ocorrendo, principalmente, pelo desenvolvimento da economia canavieira e pela fundação de engenhos, que iam gerando povoações e cidades. $\mathrm{O}$ avanço das atividades produtivas, predominantemente agrícolas (cana, gado e algodão) não estimulavam um desenvolvimento urbano mais intenso. Somente a partir da década de 1960, com as migrações da população rural que procurava na cidade novas oportunidades de trabalho, fugindo da rígida estrutura latifundiária, observa-se um adensamento populacional em algumas localidades, principalmente em Maceió.

Parte do impulso urbano vivenciado por Alagoas a partir dos anos 1970 esteve atrelado à implementação de políticas de desenvolvimento regional da Sudene, que estimulou a implantação de atividades industriais, notadamente o Polo Cloroquímico de Alagoas, mas que não produziu os resultados produtivos esperados, em virtude da crise fiscal e financeira vivenciadas pelo país, a partir dos anos 1980.

Diante da ausência de atividades industriais, o que se observou foi o crescimento do setor de serviços, principalmente aqueles com baixa remuneração, como o comércio e os serviços domésticos, e uma forte dependência do setor público na geração de emprego e renda. Ademais, os anos 1990 se caracterizaram pela significativa parcela da população vinculada à economia informal.

Essa urbanização verificada em Alagoas, com ausência de atividades industriais e grande concentração fundiária gerou uma série de problemas na infraestrutura das cidades, como o intenso crescimento da população de Maceió, que apresenta uma das maiores densidades demográficas do país, o processo de favelização, violência, ausência de saneamento básico, baixa qualidade nos transportes públicos, entre outros.

Com a criação da Região Metropolitana de Maceió, em 1998, acreditava-se que política públicas seriam implementadas, visando minimizar os problemas mencionados. No entanto, não há registros de ações efetivas sobre a área citada. Ainda assim, entre 2000 e 2010, verificam-se melhorias de alguns indicadores socioeconômicos, em virtude das políticas de redução da pobreza e desigualdade promovidas pelo governo federal, impactando nos municípios alagoanos que fazem parte da RMM.

\section{REFERÊNCIAS}


BAENINGER, Rosana. A nova configuração urbana no Brasil: desaceleração metropolitana e redistribuição da população. In: XII Encontro Nacional de Estudos Populacionais. Caxambu: ABEP, 1998.

CANO, Wilson. Ensaios sobre a crise urbana no Brasil. Campinas, SP: UNICAMP/IE, 2011.

CARVALHO, Cícero Péricles de. Economia Popular: uma via de modernização para Alagoas. 4 ed. Maceió: EdUFAL, 2010.

Formação Histórica de Alagoas. 3 ed. Maceió: Edufal, 2015.

CAVARLHO, Lina Martins de. Processo de Urbanização em área da bacia endorreica: caracterização dos padrões de ocupação dos espaços construídos e dos espaços livres de construção em Maceió - AL. Maceió/AL, 2012 (Dissertação de Mestrado). 155f.

CORREA, Roberto Lobato. O Espaço Urbano. São Paulo: Ática, 1999.

A vida urbana em alagoas: a importância dos meios de transporte na sua evolução. São Paulo: Terra Livre, 1994. P. 93-116.

COSTA, Craveiro. História das Alagoas. São Paulo: Editora Proprietária, 1983.

IBGE. Censo Demográfico, 2000. Disponível em https://sidra.ibge.gov.br/pesquisa/censodemografico/demografico-2000/inicial. Acesso em 10 dez. 2018.

IBGE. Censo Demográfico, 2010. Disponível em https://sidra.ibge.gov.br/pesquisa/censodemografico/demografico-2010/inicial. Acesso em 10 dez. 2018.

LIMA, Araken Alves. Alagoas e o complexo agroindustrial canavieiro no processo de integração nacional. Campinas/SP, 2006. (Tese de Doutorado).

LIRA, Fernando José. Formação da riqueza e da pobreza de Alagoas. Meceió: Edufal, 2007.

LOPES, Guilherme Carneiro Leão de Albuquerque. Uma análise da economia alagoana a partir dos impactos do processo de desconcentração produtiva nacional (1990-2010). Maceió/AL, 2014. (Trabalho de Conclusão de Curso). $56 \mathrm{f}$

LOPES, Alberto Costa e JUNQUEIRA, Eliana. (coord.) Habitação de Interesse Social em Maceió. Rio de Janeiro: IBAM / DUMA, 2005. 152 p

MARICATO, Ermínia. Brasil, cidades: alternativas para a crise urbana. 3 ed. Petrópolis/RJ: Vozes, 2008.

Para entender a crise urbana. São Paulo: Expressão Popular, 2015.

PNUD. Atlas do Desenvolvimento Humano no Brasil. Disponível em http://atlasbrasil.org.br/2013/pt/consulta/. Acesso em 15 dez. 2018.

SANTOS, Milton. Economia Espacial: críticas e alternativas. São Paulo: Edusp, 2011.

MARQUES, Danilo Luiz. Escravidão, Quotidiano e Gênero na Emergente Capital Alagoana (1849-1888). Sankofa Revista de História da África e de Estudos da Diáspora Africana, Ano VI, n XI, ago. 2013.

SANTANA, Moacir. Contribuição a História do Açúcar em Alagoas. Recife: Museu do Açúcar, 1970.

SANTOS FILHO, Cícero. Regiões Metropolitanas de Alagoas: entre os motivos da institucionalização e a dinâmica da integração. Maceió/AL, 2018. (Dissertação de Mestrado em Geografia). 173f.

SILVA, Alexandre Manoel Ângelo da (Org.). Economia de Maceió: diagnóstico e proposta para construção de uma nova realidade. Brasília: IPEA/Edufal, 2013.

SILVA, Jordânnya Dannyelly do Nascimento. Urbanização e Saúde em Maceió: o caso dos bairros Vergel do Lago, Jacintinho e Benedito Bentes. Maceió/AL, 2011 (Dissertação de Mestrado). 132f.

URANI, André. Um diagnóstico socioeconômico do Estado de Alagoas a partir de uma leitura dos dados da Pesquisa Nacional por Amostra de Domicílios do IBGE (1992-2004). Maceió: IETS, 2005.

TEIXEIRA, Luana. Vapores e escravos no Penedo, Alagoas, na década de 1850. Séculum Revista de História, 34, João Pessoa, jan./jun. 2016

VILLAÇA, Flávio. Espaço Intra-Urbano no Brasil. São Paulo: Estúdio Nobel, 1998. 
